Operations Research and Applications : An International Journal (ORAJ), Vol.5, No.1, February 2018

\title{
LOGNORMAL ORDINARY KRIGING METAMODEL IN SIMULATION OPTIMIZATION
}

\author{
Muzaffer Balaban $^{1}$ and Berna Dengiz ${ }^{2}$ \\ ${ }^{1}$ Turkish Statistical Institute, Ankara, Turkey \\ ${ }^{2}$ Department of Industrial Engineering, Başkent University, Ankara, Turkey
}

\begin{abstract}
This paper presents a lognormal ordinary kriging (LOK) metamodel algorithm and its application to optimize a stochastic simulation problem. Kriging models have been developed as an interpolation method in geology. They have been successfully used for the deterministic simulation optimization (SO) problem. In recent years, kriging metamodeling has attracted a growing interest with stochastic problems. SO researchers have begun using ordinary kriging through global optimization in stochastic systems. The goals of this study are to present LOK metamodel algorithm and to analyze the result of the application step-by-step. The results show that LOK is a powerful alternative metamodel in simulation optimization when the data are too skewed.
\end{abstract}

\section{KEYWORDS}

Simulation optimization, lognormal kriging, metamodel, ordinary kriging, variogram

\section{INTRODUCTION}

Simulation models have proven to be a notably powerful tool to evaluate complex systems. These evaluations are commonly in the form of responses to "what if" questions [1]. Carson and Maria [2] defined simulation optimization ( $\mathrm{SO}$ ) as the process of finding the best input variable values among all possible combinations without explicitly evaluating each possibility. According to Fu [3], SO is the optimization of performance measures based on the outputs of stochastic simulations.

The main assumption of SO is to estimate the objective function from simulation results when it is not directly available [4]. The output data obtained from stochastic simulation models are much more expensive when considering of running time than obtained by evaluating analytical functions [1]. The simulation models can be notably complex and a simplified model of these models can be constructed. This simplified model is defined as a metamodel, i.e., a "model of model". Metamodeling is the process of generating metamodels and used to find the proper functional relationship between input and output variables of a simulation model based on the computer experiment results $[5,6]$. There are several metamodel approximations in the literature. One of the metamodel methods is kriging [7]. Kriging metamodels are global instead of local [8]. Kriging metamodels have been used to analyze simulation output for the purpose of SO and sensitivity in recent years. Kriging was originally developed by Matheron [9] as a geostatistical interpolation technique to interpolate input point data and estimate a mineral resource model in the mining industry. Kriging is an optimal spatial regression technique that requires a spatial statistical model, which is popularly known as a variogram and represents the internal spatial structure of the data $[10,11]$.

Sacks et all. [12] applied the kriging model to the deterministic simulation model. Mitchell and Morris [7] mentioned that kriging model can be used as metamodel for stochastic simulation. Van Beers and Kleijnen [13] applied kriging models to stochastic simulation as an SO method. There are a few examples which used ordinary kriging $(\mathrm{OK})$ metamodel for stochastic simulation model 
Operations Research and Applications : An International Journal (ORAJ), Vol.5, No.1, February 2018

in the literature [13, 14, and 15]. Ankerman et all. [16] applied stochastic kriging which is an extension of basic kriging theory to the stochastic simulation metamodelling. Mehdad and Kleijnen [17] applied intrinsic kriging to the stochastic simulation metamodelling.

This paper focuses on the lognormal ordinary kriging (LOK) metamodels to use optimization of a stochastic simulation problem. When the simulation output data are significantly skewed, the predicted outputs are not normally distributed. The logarithmic transformation of the output data can provide a better solution [18]. From this viewpoint, in this paper, a LOK metamodel algorithm is proposed to optimize the cost of the communication network system, which was originally described by Barton and Meckesheimer [5]. They used logarithmic transformed outputs in regression metamodeling.

Our own C++ source code is driven for our proposed LOK algorithm. To the best of our knowledge, there is no other study for LOK modeling through SO. LHD is used for the simulation experiments to prevent a high correlation among the experiments to maintain the random structure of the design. The LOK metamodel has been successfully applied to the considered problem. In addition, a sensitivity analysis was made for the SO results. The performance of the proposed LOK metamodel in optimizing the total cost of the communication network system was compared with the OK and regression metamodels. LOK metamodel provides a higher-quality solution than the regression and OK from the optimization viewpoint.

Based on the findings of this study, LOK can be used as a powerful alternative metamodel in stochastic SO when the simulation outputs are significantly skewed.

The remainder of this paper is organized as follows. In section 2, kriging method is discussed, including the basic assumptions and mathematical formulas of ordinary and lognormal kriging. In section 3, the problem statement, experimental design, simulation and application of lognormal kriging to simulation results and the optimization results are explained. Section 4 presents the conclusions.

\section{KRIGING MethoD}

Kriging is an optimal, unbiased prediction method of regionalized variables at unsampled locations using the structural properties of the variogram and the initial set of data values [19]. The output data are weighted based on the variogram model in the kriging models. Kriging provides the prediction variance at every predicted point, which indicates the accuracy of the predicted value. The effectiveness of kriging depends on the correct specification of the theoretical variogram model. More details on the kriging techniques are provided in the classical reference books by Journal and Huijbregts [20], Isaaks and Srivastava [21] and Cressie [11]. Furthermore, a comparative study between regression and kriging metamodels is presented in Kleijnen [8].

The objective of kriging is to predict the value of a random variable, $\mathrm{Z}(\mathrm{x})$, at new points in a region $\mathrm{D}$ from experimented data $\left\{\mathrm{z}\left(\mathrm{x}_{1}\right), \mathrm{z}\left(\mathrm{x}_{2}\right), \ldots, \mathrm{z}\left(\mathrm{x}_{\mathrm{n}}\right)\right\}$ at points $\left\{\mathrm{x}_{1}, \mathrm{x}_{2}, \ldots, \mathrm{x}_{\mathrm{n}}\right\}$. Let us assume that we want to predict $\mathrm{Z}\left(\mathrm{x}_{0}\right)$ at $\mathrm{x}_{0}$. For the predictor $\mathrm{Z}\left(\mathrm{x}_{0}\right)$, we use a linear combination of experimented points. $\hat{Z}\left(x_{0}\right)=\sum_{i}^{n} \lambda_{i} Z\left(x_{i}\right)$ is a weighted average of observed data with weights $\lambda_{\mathrm{i}}$. We want the prediction to be unbiased as shown in equation (1).

$$
\mathrm{E}\left(\widehat{\mathrm{Z}}\left(\mathrm{x}_{0}\right)\right)=\mathrm{E}\left(\mathrm{Z}\left(\mathrm{x}_{0}\right)\right)
$$


Operations Research and Applications : An International Journal (ORAJ), Vol.5, No.1, February 2018

\subsection{VARIOGRAM}

The variogram (semivariance or semivariogram) estimation is a notably important step of the kriging process because it determines the kriging weights [22]. The original semivariogram term was used by Matheron because it is one half of a variance [23].

$\mathrm{Z}(\mathrm{x})=\left\{\mathrm{z}\left(\mathrm{x}_{1}\right), \mathrm{z}\left(\mathrm{x}_{2}\right), \ldots, \mathrm{z}\left(\mathrm{x}_{\mathrm{n}}\right)\right\}$ is the experimental data set, which consists of the outputs of the simulation model that satisfies the second order and intrinsic stationary. Matheron [9] defined a logical estimator of experimental variogram as shown in (2).

$$
\gamma(\mathrm{h})=\frac{1}{2 \mathrm{~N}(\mathrm{~h})} \sum_{\mathrm{i}=1}^{\mathrm{N}(\mathrm{h})}\left(\mathrm{Z}\left(\mathrm{x}_{\mathrm{i}}\right)-\mathrm{Z}\left(\mathrm{x}_{\mathrm{i}}+\mathrm{h}\right)\right)^{2}
$$

where $\mathrm{N}(\mathrm{h})$ is the number of pairs, $\left(\mathrm{Z}\left(\mathrm{x}_{\mathrm{i}}\right), \mathrm{Z}\left(\mathrm{x}_{\mathrm{i}}+\mathrm{h}\right)\right)$, and $\mathrm{h}$ is the distance between the experiments [23]. Cresssie and Hawkins [24] proposed a robust variogram estimator as shown in (3).

$$
\gamma(\mathrm{h})=\frac{1}{2}\left[\frac{1}{\mathrm{~N}(\mathrm{~h})} \sum_{\mathrm{i}=1}^{\mathrm{N}(\mathrm{h})}\left(\mathrm{Z}\left(\mathrm{x}_{\mathrm{i}}\right)-\mathrm{Z}\left(\mathrm{x}_{\mathrm{i}}+\mathrm{h}\right)\right)^{\frac{1}{2}}\right]^{4} /\left(0.457+\frac{0.494}{\mathrm{~N}(\mathrm{~h})}\right)
$$

When we calculate the kriging weights for each non-experimental point, we need a theoretical variogram model, which must fit the experimental variogram. Myers [23] has listed four variogram models as a function of distance $h$.

In this study, the exponential variogram model in (4) is used as the fitted theoretical variogram model to the experimental variogram, where $\mathrm{a}_{0}, \mathrm{a}_{1}$ and $\mathrm{a}_{2}$ are the model parameters.

$$
\gamma(h)=\left\{\begin{array}{rr}
a_{o}+a_{1}\left[1-\exp \left(\frac{-h}{a_{2}}\right)\right] & \text { if } h \neq 0 \\
0 & \text { if } h=0
\end{array}\right.
$$

\subsection{ORDINARY KRIGING}

The random variable $\mathrm{Z}(\mathrm{x})$ satisfies two model assumptions in equations (5) and (6) $[9,10,23$, and $11]$.

$$
\mathrm{Z}(\mathrm{x})=\mu+\varepsilon(\mathrm{x})
$$

$\mathrm{E}(\mathrm{Z}(\mathrm{x}))=\mu$ is constant and unknown

The kriging predictor is given in equation (7) and satisfies equation (8).

$$
\begin{gathered}
\hat{\mathrm{Z}}\left(\mathrm{x}_{0}\right)=\sum_{\mathrm{i}}^{\mathrm{n}} \lambda_{\mathrm{i}} \mathrm{Z}\left(\mathrm{x}_{\mathrm{i}}\right) \\
\sum_{\mathrm{i}}^{\mathrm{n}} \lambda_{\mathrm{i}}=1
\end{gathered}
$$

The mean square prediction error is calculated in equation (9).

$$
\left(\mathrm{Z}\left(\mathrm{x}_{0}\right)-\hat{\mathrm{Z}}\left(\mathrm{x}_{0}\right)\right)^{2}=\left(\mathrm{Z}\left(\mathrm{x}_{0}\right)-\sum_{\mathrm{i}}^{\mathrm{n}} \lambda_{\mathrm{i}} \mathrm{Z}\left(\mathrm{x}_{\mathrm{i}}\right)\right)^{2}=-\sum_{\mathrm{i}}^{\mathrm{n}} \sum_{\mathrm{j}}^{\mathrm{n}} \lambda_{\mathrm{i}} \lambda_{\mathrm{j}} \gamma\left(\mathrm{x}_{\mathrm{i}}-\mathrm{x}_{\mathrm{j}}\right)+
$$


Operations Research and Applications : An International Journal (ORAJ), Vol.5, No.1, February 2018

$$
2 \sum_{\mathrm{i}}^{\mathrm{n}} \lambda_{\mathrm{i}} \gamma\left(\mathrm{x}_{0}-\mathrm{x}_{\mathrm{i}}\right)
$$

The constrained minimization problem in equations (10) and (11) is suitable to find

$$
\lambda=\left(\lambda_{1}, \ldots, \lambda_{n}\right)^{\prime} \text {. }
$$

$$
\operatorname{Min}\left(\mathrm{Z}\left(\mathrm{x}_{0}\right)-\hat{\mathrm{Z}}\left(\mathrm{x}_{0}\right)\right)^{2}
$$

subject to

$$
\sum_{i}^{n} \lambda_{i}=1
$$

Lagrange multipliers method is convenient to solve this constrained minimization problem. Thus, by substituting equations (10) and (11) into $L(\lambda, m)$, equation (12) is obtained.

$$
L(\lambda, m)=-\sum_{i}^{n} \sum_{j}^{n} \lambda_{i} \lambda_{j} \gamma\left(x_{i}-x_{j}\right)+2 \sum_{i}^{n} \lambda_{i} \gamma\left(x_{0}-x_{i}\right)-2 m\left(\sum_{i}^{n} \lambda_{i}-1\right)
$$

Differentiating with respect to $\lambda_{\mathrm{i}}$ and $\mathrm{m}$, we obtain the following system of linear equations.

$$
\begin{gathered}
\sum_{\mathrm{j}}^{\mathrm{n}} \lambda_{\mathrm{j}} \gamma\left(\mathrm{x}_{\mathrm{i}}-\mathrm{x}_{\mathrm{j}}\right)+\mathrm{m}=\gamma\left(\mathrm{x}_{\mathrm{o}}-\mathrm{x}_{\mathrm{i}}\right), \text { for } \mathrm{i}=1,2, \ldots, \mathrm{n} \\
\sum_{\mathrm{i}}^{\mathrm{n}} \lambda_{\mathrm{i}}=1
\end{gathered}
$$

The system of equations in equations (13) and (14) can be written in a matrix form as shown in equation (15).

$$
\Gamma_{\mathrm{o}} \lambda_{\mathrm{o}}=\gamma_{\mathrm{o}}
$$

Where

$$
\begin{aligned}
& \Gamma_{\mathrm{o}}=\left|\begin{array}{lllcl}
\gamma\left(\mathrm{x}_{1}-\mathrm{x}_{1}\right) & \gamma\left(\mathrm{x}_{1}-\mathrm{x}_{2}\right) & \ldots & \gamma\left(\mathrm{x}_{1}-\mathrm{x}_{\mathrm{n}}\right) & 1 \\
\ldots & \ldots & \ldots & \ldots & \ldots \\
\gamma\left(\mathrm{x}_{\mathrm{n}}-\mathrm{x}_{1}\right) & \gamma\left(\mathrm{x}_{\mathrm{n}}-\mathrm{x}_{2}\right) & \ldots & \gamma\left(\mathrm{x}_{\mathrm{n}}-\mathrm{x}_{\mathrm{n}}\right) & 1 \\
1 & 1 & \ldots & 1 & 0
\end{array}\right| \\
& \gamma_{\mathrm{o}}=\left(\gamma\left(\mathrm{x}_{1}-\mathrm{x}_{\mathrm{o}}\right), \gamma\left(\mathrm{x}_{2}-\mathrm{x}_{\mathrm{o}}\right), \ldots \ldots, \gamma\left(\mathrm{x}_{\mathrm{n}}-\mathrm{x}_{\mathrm{o}}\right), 1\right) \\
& \lambda_{\mathrm{o}}=\left(\lambda_{1}, \lambda_{2}, \ldots, \lambda_{\mathrm{n}}, \mathrm{m}\right)
\end{aligned}
$$

This system has a unique solution for $\lambda_{\mathrm{o}}$ if and only if $\Gamma_{\mathrm{o}}$ is invertible. Thus, equation (19) is obtained.

$$
\lambda_{\mathrm{o}}=\Gamma^{-1} \gamma_{\mathrm{o}}
$$

$\mathrm{Z}\left(\mathrm{x}_{0}\right)$ is predicted using equation (20).

$$
\hat{\mathrm{Z}}\left(\mathrm{x}_{0}\right)=\lambda^{\prime} \mathrm{Z}
$$


We must only recalculate $\gamma_{0}$ for a new point $\mathrm{x}_{0}$ using the fitted theoretical variogram model. Matrix $\Gamma_{0}$ does not change for new positions of $x_{0}$ but only changes when the experimental data are modified or another variogram model is selected. The minimized prediction variance is also called the kriging variance and denoted by $\sigma^{2}\left(\mathrm{x}_{0}\right)[10]$.

$$
\begin{aligned}
& \sigma^{2}\left(x_{0}\right)=\sum_{i}^{n} \lambda_{i} \gamma\left(x_{i}-x_{0}\right)+m \\
& \sigma^{2}\left(x_{0}\right)=\lambda_{0} \cdot \gamma_{o}
\end{aligned}
$$

$\sigma^{2}\left(x_{0}\right)$ in equations (21) and (22) are easily calculated given $\lambda_{0}$ and $\gamma_{0}$.

\subsection{LOGNORMAL KRIGING}

If the outputs are too skewed, the normality assumption for the kriging prediction is violated. Therefore, a data transformation is used to solve this problem [18].

Let $\mathrm{Z}(\mathrm{x})$ denotes a random process. Logarithmic transformation of $\mathrm{Z}(\mathrm{x})$ given in the equation (23) is normally distributed.

$$
\mathrm{Y}(\mathrm{x})=\ln \mathrm{Z}(\mathrm{x}), \mathrm{x} \in \mathrm{D}
$$

The aim of this transformation is to predict a random variable $\mathrm{Z}\left(\mathrm{x}_{\mathrm{o}}\right)$. The main step here is to transform the problem from $\mathrm{Z}$ to the intrinsically stationary normally distributed $\mathrm{Y}$. The predictor of $\mathrm{Y}\left(\mathrm{x}_{0}\right)$ is given in equation (24).

$$
\widehat{Y}\left(x_{0}\right)=\sum_{i}^{n} \lambda_{i} \ln Z\left(x_{i}\right)=\sum_{i}^{n} \lambda_{i} Y\left(x_{i}\right)
$$

The back-transformation of $\widehat{\mathrm{Y}}\left(\mathrm{x}_{0}\right), \widehat{\mathrm{Z}}\left(\mathrm{x}_{0}\right)$, is unbiased with equation (25),

$$
\widehat{\mathrm{Z}}\left(\mathrm{x}_{0}\right)=\exp \left(\widehat{\mathrm{Y}}\left(\mathrm{x}_{0}\right)+\frac{\sigma_{\mathrm{Y}, \mathrm{k}}^{2}}{2}-\mathrm{m}_{\mathrm{Y}}\right)
$$

where $\sigma_{\mathrm{Y}, \mathrm{k}}^{2}$ is the kriging variance of $\mathrm{Y}$, and $\mathrm{m}_{\mathrm{Y}}$ is the Lagrange multiplier defined in equation (12) [11]. In the literature, there are several theoretical studies of LOK such as Journel and Huijbregts [20] and Dowd [25], and some useful application of LOK in geology such as Gilbert and Simpson [26], Mc Grath and Zhangb [27], Paul and Cressie [28] and Lark and Lapworth [29].

\section{Simulation OPTIMIZATION APPLICATION With LOGNORMAL KRIGING}

\subsection{Problem Statement}

In this part of the study, a communication network system is considered to apply the proposed LOK metamodeling approach. Figure 1 shows the flow chart of the network, which consists of three sub-networks $i=1,2,3$ with randomly arriving messages. The problem in this system is to find message routing percentages (as input factors) through the communication network. The objective of this problem is to minimize the total cost (c) of the system with the three subnetworks [5]. Messages go to network 1 with probability $\mathrm{p}_{1}$, the remaining messages go to network 2 with probability $\mathrm{p}_{2}$; the remaining messages go to network 3 as shown in Figure 1 . The total system cost is computed with the assumptions that per time unit cost for each message is $\$ 0.005$ and the message processing costs $a_{i}$ are $\$ 0.03, \$ 0.01$, and $\$ 0.005$ for the three networks. The inter-arrival time of messages has an exponential distribution with a mean of 1 time unit. The 
network transit times have triangular distributions with a mean of $\mathrm{E}\left(\mathrm{S}_{\mathrm{i}}\right)=\mathrm{i}$ and limits $+/-0.5$ for each network i.

The objective of this problem is to find the routing probabilities $\left(\mathrm{p}_{1}, \mathrm{p}_{2}\right)$ that minimize the total cost of the system. Hence, $p_{1}$ and $p_{2}$ are the input set of the SO problem. Then, $x_{1}$ and $x_{2}$, which are the decision variables of this problem, are replaced by $\mathrm{p}_{1}$ and $\mathrm{p}_{2}$, and $\mathrm{Z}(\mathrm{x})$ is used to indicate the average total cost of the system to define the considered optimization problem.

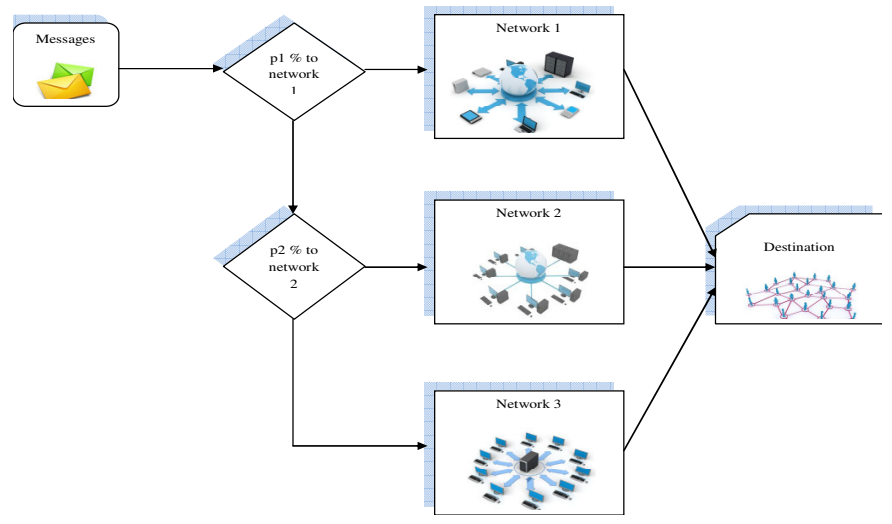

Figure 1. Flow chart of the considered communication network system

Barton and Meckesheimer [5] used the logarithmic transformed outputs in their study and a regression metamodel to optimize the total cost of the communication network system to determine the routing percentages $\left(\mathrm{p}_{1}, \mathrm{p}_{2}\right)$. Their strategy was to sequentially explore the local subregions of the experimental region to find a new experimental subregion closer to the optimum. This strategy applied five iterations to the problem. A disadvantage of the method is that the automated versions of the algorithm are not available. Global metamodels present an opportunity for optimization using a single metamodel instead of a sequence of fitted local metamodels. As a global metamodel, kriging can be fitted once based on a set of simulations from a global experiment design; then, the optimization can iteratively proceed using the same metamodel [5].

A simulation model of the system is built and coded using the Arena platform (Arena 14) with discrete event simulation. To compute the cost of the system, we define the simulation length to be 1000 messages. We define the input set $\mathrm{x}_{1}=0.33$ and $\mathrm{x}_{2}=0.50$ for the initial run to validate the simulation model and define the number of replicates. The number of independent replicates is set as 10 . The mean total cost of the system is 61.76 , and the variance of the cost is 243.84 .

\subsection{EXPERIMENTAL DESIGN For KRIGING}

Latin hypercube designs (LHDs) are often used to find the fitted kriging metamodel for I/O simulation data $[8,30]$. LHDs are particularly well suited for kriging because they can cover the design space [14]. LHD was first described for computer experiments by McKay et al. [31]. LHDs are produced by Latin hypercube sampling, i.e., dividing each factor axis into $\mathrm{n}$ equal intervals [32]. Firstly, the number of design points, $n$, to be used in LHD is decided. Then range of each input variable is divided into $n$ equally probable intervals. An $\mathrm{n} \times \mathrm{n}$ design matrix is obtained for two input factors. In LHD, each column and row has one design point randomly assigned [33].

A randomly generated LHD may cause two problems. First, the factors may be perfectly correlated. Second, a large area may be unexplored in the experimental region. There are some studies in the literature to avoid these problems [34]. The main idea of these studies is optimizing LHDs for space filling. 
Operations Research and Applications : An International Journal (ORAJ), Vol.5, No.1, February 2018

In this study, a random LHD algorithm is used to obtain the design points, and the design region is divided into four blocks to ensure that the design points cover the design space to avoid the perfect correlation among the input variables. The random LHD algorithm is coded in C++.

LHD is used for two-dimensional input variables as the experimental design strategy. The design region is considered as $\mathrm{x}_{1}=(0.35-0.80), \mathrm{x}_{2}=(0.35-0.80)$ for each input variable. The selected number of design points is 16 because obtaining data from the stochastic simulation model is expensive. The simulation model runs 10 replications for each 16 design points. The average simulation outputs are listed in Table 1.

Table 1. Simulation outputs for the design points.

\begin{tabular}{|l|l|l|l|l|}
\hline $\begin{array}{l}\text { Design } \\
\text { points }\end{array}$ & $\begin{array}{l}\mathbf{x}_{\mathbf{1}} \\
\boldsymbol{\%}\end{array}$ & $\begin{array}{l}\mathbf{x}_{\mathbf{2}} \\
\mathbf{\%}\end{array}$ & $\mathbf{Z ( x )}$ & $\ln \mathbf{Z}(\mathbf{x})$ \\
\hline 1 & 35 & 77 & 88.98 & 4.488 \\
\hline 2 & 38 & 38 & 175.70 & 5.169 \\
\hline 3 & 41 & 59 & 35.15 & 3.560 \\
\hline 4 & 44 & 47 & 41.30 & 3.721 \\
\hline 5 & 47 & 68 & 33.76 & 3.519 \\
\hline 6 & 50 & 74 & 35.21 & 3.561 \\
\hline 7 & 53 & 71 & 33.80 & 3.520 \\
\hline 8 & 56 & 62 & 33.20 & 3.502 \\
\hline 9 & 59 & 56 & 33.65 & 3.516 \\
\hline 10 & 62 & 44 & 34.80 & 3.550 \\
\hline 11 & 65 & 53 & 34.28 & 3.535 \\
\hline 12 & 68 & 65 & 34.81 & 3.550 \\
\hline 13 & 71 & 80 & 35.70 & 3.575 \\
\hline 14 & 74 & 41 & 37.28 & 3.619 \\
\hline 15 & 77 & 50 & 38.89 & 3.661 \\
\hline 16 & 80 & 35 & 40.58 & 3.703 \\
\hline
\end{tabular}

\subsection{Lognormal Ordinary Kriging Algorithm}

The following LOK algorithm is proposed to find the total average $\operatorname{cost} \mathrm{Z}(\mathrm{x})$ with the input sets $\mathrm{x}_{1}$ and $\mathrm{x}_{2}$. 


\section{Lognormal Ordinary Kriging Metamodel Algorithm for SO}

Step 1: Input: $\left.x_{i}=\left(x_{1 i}, x_{2 i}\right), Z\left(x_{i}\right), Y\left(x_{i}\right)=\ln \mid Z\left(x_{i}\right)\right)$ for $i=1$ to $n$

Step 2: a) Calculate the semivariance of each pair of experiments $\gamma(\mathrm{i}, \mathrm{j})=0.5^{*} \operatorname{Var}\left(\mathrm{Y}\left(\mathrm{x}_{\mathrm{i}}\right), \mathrm{Y}\left(\mathrm{x}_{\mathrm{j}}\right)\right)$

b) Calculate the distance of each pair of experiments.

$$
h\left(i_{j} j\right)=\sqrt{\left(x_{1 i}-x_{1 j}\right)^{2}+\left(x_{2 i}-x_{2 j}\right)^{2}}
$$

Step 3: a) Create the Experimental Variogram $\Gamma_{e}$

b) Find the Fitted Theoretical Variogram Model $\gamma(\mathrm{h})$

c) Create the Theoretical Variogram $\Gamma_{\text {。 }}$

d) Calculate the Inverse of the Theoretical Variogram $\Gamma_{0}^{-1}$

Step 4: Set $\mathrm{Z}^{*}, \mathrm{x}_{1}{ }^{*}, \mathrm{x}_{2}{ }^{*}$ initial optimal values

Step 5: a) Set the factor values $x_{0}=\left(x_{1}, x_{2}\right)$ for new estimation points $x_{1}$ from 35 to 80 and

$$
x_{2} \text { from } 35 \text { to } 80
$$

b) Calculate the distance between the new estimation point and the experiments. $\mathrm{h}(0, \mathrm{i})=\sqrt{\left(\mathrm{x}_{1}-\mathrm{x}_{1 \mathrm{i}}\right)^{2}+\left(\mathrm{x}_{2}-\mathrm{x}_{2 \mathrm{i}}\right)^{2}}$

c) Calculate the Variogam vector using the Theoretical Variogram Model $\gamma(0)$

Step 6: a) Calculate the OK coefficient $\lambda_{\mathrm{i}}=\Gamma_{\mathrm{t}}^{-1} \gamma(0)$

b) Calculate the cost for the new factors.

$$
\mathrm{Y}\left(\mathrm{x}_{0}\right)=\sum_{\mathrm{i}=1}^{\mathrm{n}} \lambda_{\mathrm{i}} \mathrm{Y}\left(\mathrm{x}_{\mathrm{i}}\right) \text { and } \mathrm{Z}\left(\mathrm{x}_{0}\right)=\exp \left(\mathrm{Y}\left(\mathrm{x}_{0}\right)+\frac{\sigma_{\mathrm{Y}, \mathrm{k}}^{2}}{2}-\mathrm{m}_{\mathrm{Y}}\right)
$$

Step 7 a) If $\mathrm{Z}\left(\mathrm{x}_{0}\right)<\mathrm{Z}^{*}$ set $\mathrm{x}_{1}{ }^{*}=\mathrm{x}_{1}, \mathrm{x}_{2}{ }^{*}=\mathrm{x}_{2}, \mathrm{Z}^{*}=\mathrm{Z}\left(\mathrm{x}_{0}\right)$

b) If all combinations of factors are evaluated, go to step 8 Otherwise, go to step 5

Step 8: Report the kriging results. $\mathrm{Z}^{*}, \mathrm{x}_{1}{ }^{*}, \mathrm{x}_{2}{ }^{*}$

Step 9: Validate the kriging result using the simulation model

The Design and Analysis of Computer Experiments (DACE) is a Matlab toolbox. This software is typically used to construct a kriging approximation model based on data from a computer experiment, and this approximation model is used as a surrogate for the computer model [35]. The DACE toolkit is generally used in kriging metamodeling for simulation optimization [13, 14, and 8]. In our study, our own C++ source code is driven for our proposed LOK algorithm. To the best of our knowledge, there is no other study for LOK modeling through SO.

A logarithmic transformation is used to simulate the output data obtained with the LHD because of the high variation among the replicates as discussed in section 2.3. Barton and Meckesheim [5] used logarithmic transformed outputs in their regression metamodelling study. After the variogram analysis as discussed in section 2.1 , the exponential variogram model is selected as a fitted variogram model: $\gamma(\mathrm{h})=0.3^{*}(1-\exp (-\mathrm{h} / 20))$, as shown in figure 2 . The LOK metamodel and a searching algorithm are used for the entire response region with $45 \times 45$ input grids of $x_{1}$ and $\mathrm{x}_{2}$ to find the minimum expected value of $Z$. The search algorithm seeks the minimum among all estimated Zs of possible combinations of the input set of $\mathrm{x}_{1}$ and $\mathrm{x}_{2}$. The minimum output of the LOK model is estimated as $Y^{*}=3.4988$ with the set of input variables as $\left(\mathrm{x}_{1}{ }^{*}, \mathrm{x}_{2}{ }^{*}\right)=(55,63)$ with kriging variance $\sigma_{Y, k}^{2}=0.0353$ and Lagrange multiplier $\mathrm{m}_{\mathrm{Y}}=0$.

The back-transformation of $\ln \mathrm{Z}^{*}$ to $\mathrm{Z}^{*}$ is $\mathrm{Z}^{*}=\exp (3.4988+0.0353 / 2)=33.6647$, which gives the correct estimated optimum output, because the log transformation is monotonic. 
Operations Research and Applications : An International Journal (ORAJ), Vol.5, No.1, February 2018

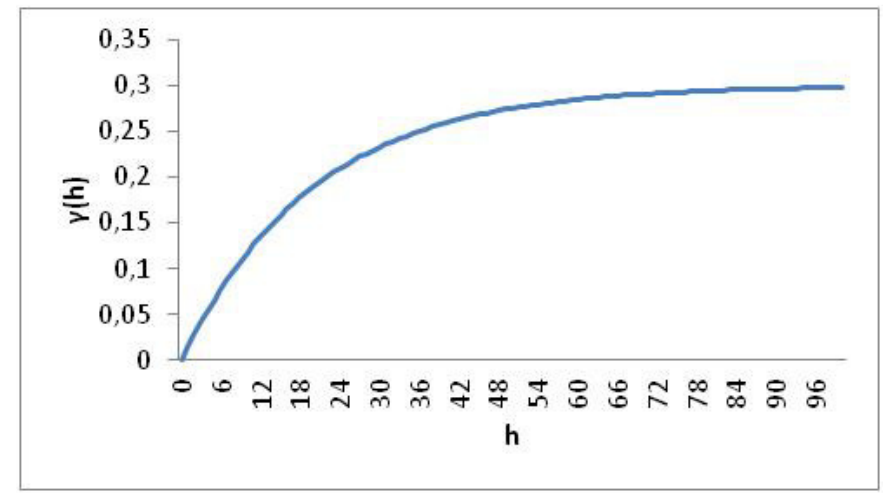

Figure 2. Fitted theoretical variogram models.

The metamodel of the considered problem is also modeled by OK to compare the results of the LOK metamodel. The exponential variogram model is selected as the fitted variogram model $(\gamma(\mathrm{h})=3650 *(1-\exp (-\mathrm{h} / 61)))$. A point map is created for the entire response region with $45 \times 45$ input grids of $x_{1}$ and $x_{2}$ to find the minimum $Z$ using the OK. A minimum output of the OK metamodel is $Z^{*}=30.05$ at $\left(\mathrm{x}_{1}{ }^{*}, \mathrm{x}_{2}{ }^{*}\right)=(49,58)$, whereas the LOK gave $Z^{*}=33.664$ at $(55,63)$.

\subsection{Validation Of Kriging Results Through Simulation And Neighborhood SEARCH}

The last step of the proposed SO is the result validation. The simulation model of the system and the neighborhood search approach are used to obtain a better solution. This step is important to eliminate the kriging errors. The simulation output analysis results in $\mathrm{Z}^{*}=32.99$ with the variance $\hat{\sigma}^{2}=0.1702$ for the factors $\left(\mathrm{x}_{1}{ }^{*}, \mathrm{x}_{2}{ }^{*}\right)=(55,63)$.

Biles et all. [14] suggested that some neighbors of the predicted optimal point should be simulated after the kriging process to improve solution. This step is called the sensitivity analysis [36]. Their approach is to explore the experimental area defined around the optimum point.

In this study, firstly, the two neighbor points of $\left(\mathrm{x}_{1}{ }^{*}, \mathrm{x}_{2}{ }^{*}\right)=(55,63),\left(\mathrm{x}_{1}, \mathrm{x}_{2}\right)=(55,64)$ and $\left(\mathrm{x}_{1}, \mathrm{x}_{2}\right)=(55,65)$, are selected for simulation to obtain a better solution. Then, the direction $\left(\mathrm{x}_{1}, \mathrm{x}_{2}\right)=(54,63)$ is simulated. Finally, the two points, $\left(\mathrm{x}_{1}, \mathrm{x}_{2}\right)=(53,63),\left(\mathrm{x}_{1}, \mathrm{x}_{2}\right)=(52,63)$ are simulated respectively. The average results of 10 replicates are given in Table 2 . The design point $\left(\mathrm{x}_{1}, \mathrm{x}_{2}\right)=(53,63)$ is the best point among them with $\mathrm{Z}(\mathrm{x})=32.97$ and variance, $\hat{\sigma}^{2}=0.0962$.

Table 2. Simulation results for the neighbors of the kriging results.

\begin{tabular}{|l|l|l|l|}
\hline $\begin{array}{l}\text { Neighbor } \\
\text { points }\end{array}$ & $\begin{array}{l}\mathbf{x}_{\mathbf{1}} \\
\mathbf{\%}_{\mathbf{0}}\end{array}$ & $\begin{array}{l}\mathbf{x}_{\mathbf{2}} \\
\mathbf{\%}_{\mathbf{0}}\end{array}$ & $\mathbf{Z ( x )}$ \\
\hline 1 & 55 & 63 & 32.99 \\
\hline 2 & 55 & 64 & 32.98 \\
\hline 3 & 55 & 65 & 33.09 \\
\hline 4 & 54 & 63 & 32.98 \\
\hline $\mathbf{5}$ & $\mathbf{5 3}$ & $\mathbf{6 3}$ & $\mathbf{3 2 . 9 7}$ \\
\hline 6 & 52 & 63 & 33.04 \\
\hline
\end{tabular}

The simulation model is also validated for the optimum point OK metamodel, $\left(\mathrm{x}_{1}{ }^{*}, \mathrm{x}_{2}{ }^{*}\right)=(49,58)$. The simulation output analysis results have $\mathrm{Z}^{*}=33.22$ and variance $\hat{\sigma}^{2}=$ 0.4501 . 
Table 3 summarizes the results of the LOK, OK and regression metamodels and their confidence intervals. Using the $\mathrm{SO}$ with regression and kriging metamodels of the considered communication network system, the estimated average costs are 32.97, 33.22 and 33.04. The LOK metamodel finds the best routing percentages $\left(\mathrm{p}_{1}=53 \%, \mathrm{p}_{2}=63 \%\right)$ and minimizes the overall system cost. Although there is no statistically significant difference among the LOK, OK and regression results at $\alpha=0.05$ significant levels, the LOK metamodel has narrower confidence intervals than the OK and regression metamodel strategy. Thus, the LOK algorithm provides a higher-quality solution than the regression and OK from the optimization viewpoint.

Table 3. SO results with kriging and regression meta model.

\begin{tabular}{|l|l|l|l|l|}
\hline Metamodels & $\begin{array}{l}\mathbf{p}_{1} \\
\mathbf{\%}\end{array}$ & $\begin{array}{l}\mathbf{p}_{2} \\
\mathbf{\%}\end{array}$ & Cost & $\begin{array}{l}\text { Confidence Intervals of } \\
\text { Cost with } \mathbf{\alpha}=\mathbf{0 . 0 5} \\
\text { significant level }\end{array}$ \\
\hline LOK & 53 & 63 & 32.97 & {$[32.75,33.19]$} \\
\hline OK & 49 & 58 & 33.22 & {$[32.74,33.70]$} \\
\hline Regression & 54 & 63.8 & 33.04 & {$[32.67,33.41]$} \\
\hline
\end{tabular}

\section{CONCLUSIONS}

This paper discusses the LOK metamodel to optimize the cost of communication network systems, when the simulation output data are significantly skewed. This study also demonstrates the implementation of LOK metamodel in SO. Firstly, LHD is used for the simulation experiments to prevent a high correlation among the experiments to maintain the random structure of the design. Then, the LOK algorithm is developed and coded in C++ platform. The LOK algorithm is applied to the simulation results. The kriging results are validated by the simulation model. In addition, a sensitivity analysis was made for the SO results. LOK metamodel provides a higher-quality solution than the regression and OK from the optimization viewpoint.

According to the best of our knowledge, the LOK is first used as a metamodel for SO. Based on the literature and the findings of this study, the LOK is an alternative metamodel method to traditional regression approaches and $\mathrm{OK}$ metamodel in SO, when the simulation output data are significantly skewed.

Future studies will concentrate on the development of high-dimensional LOK and its software integrated with heuristic optimization algorithm for SO purposes.

\section{REFERENCES}

[1] Azadivar, F. (1992) "A tutorial on simulation optimization", Proceedings of the 1992 Winter Simulation Conference, pp.198-204.

[2] Carson, Y., Maria, A. (1997) "Simulation optimization: methods and applications", Proceedings of the 1997 Winter Simulation Conference, pp.118-126.

[3] Fu, M.C. (2001) "Simulation optimization", Proceedings of the 2001 Winter Simulation Conference, pp.53-61.

[4] Fu, M.C., Glover, F.W. \& April, J. (2005) "Simulation optimization: a review, new developments, and applications", Proceedings of the 2005 Winter Simulation Conference.

[5] Barton, R. R. \& Meckesheimer, M. (2006) "Metamodel-based simulation optimization in simulation", Handbooks in Operations Research and Management Science, Vol.13, pp.535-574. 
Operations Research and Applications : An International Journal (ORAJ), Vol.5, No.1, February 2018

[6] Kleijnen, J.P.C. (1979) "Regression metamodels for generalizing simulation results", IEEE Transactions on systems, man and cybernetics, SMC-9, Vol.2, pp. 93-96.

[7] Mitchell, T. J. \& Morris, M. D. (1992) "Bayesian design and analysis of computer experiments: two examples", Statistica Sinica, Vol.2, pp.359-379.

[8] Kleijnen, J.P.C. (2009) "Kriging metamodeling in simulation: a review”, European Journal of Operational Research, Vol.192, pp.707-716.

[9] Matheron, G. (1963) "Principles of geostatistics", Economic Geology, Vol.58, pp.1246-1266.

[10] Cressie, N.A.C. (1990) “The origins of kriging”, Mathematical Geology, Vol.22, pp.239-252.

[11] Cressie, N.A.C. (1993) Statistics for Spatial Data, New York: A Wiley-Interscience publication.

[12] Sacks, J., Welch, W.J., Mitchell, T.J. \& Wynn, H.P. (1989) "Design and analysis of computer experiments", Statistical Science, Vol.4, pp.409-435.

[13] Van Beers, W. \& Kleijnen, J.P.C. (2003) "Kriging for interpolation in random simulation", Journal of the Operational Research Society, Vol.54, pp.255-262.

[14] Biles, W. E., Kleijnen, J.P.C., Van Beers, W.C.M. \& Van Nieuwenhuyse, I. (2007) "Kriging metamodeling in constrained simulation optimization: an explorative study", Proceedings of the 2007 Winter Simulation Conference.

[15] Zakerifar, M., Biles, W.E. \& Evans, G.W. (2009) "Kriging metamodeling in multi-objective simulation optimization", Proceedings of the 2009 Winter Simulation Conference.

[16] Ankenman, B., Nelson, B.L., \& Staum, J. (2010) "Stochastic kriging for simulation metamodeling", Operations Research, Vol.58:2, pp.371-382.

[17] Mehdad \& Kleijnen JPC. (2018) "Stochastic intrinsic kriging for simulation metamodeling", Applied Stochastic Models Bus Ind., pp.1-16.

[18] Roth, C. (1998) "Is lognormal kriging suitable for local estimation?” Mathematical Geology, Vol. 30: 8, pp.999-1009.

[19] David, M. (1977) Geostatistical Ore Reserve Estimation, Amsterdam: Elsevier.

[20] Journel, A., G. \& Huijbregts C. J. (1978) Mining Geostatistics, London, Academic Press.

[21] Isaaks, E.H. \& Srivastava, R.M. (1989) An Introduction to Applied Geostatistics, Toronto, Oxford University Press.

[22] Genton, M. G. (1998) "Highly robust variogram estimation”, Mathematical Geology, Vol.30:2, pp.213-221.

[23] Myers, D.E. (1991) "On variogram estimation", The frontiers of statistical scientific theory \& industrial applications, Vol. 2, pp.261-266.

[24] Cressie, N.A.C. \& Hawkins, D.M. (1980) "Robust estimation of the variogram: I", Mathematical Geology, Vol.12: 2, pp.115-125.

[25] Dowd, P.A. (1982) "Lognormal kriging: the general case", Mathematical Geology, Vol.14: 5, pp. 474-500.

[26] Gilbert, R.O. \& Simpson, J.C. (1985) "Kriging for estimation spatial pattern of contaminants: potential and problems", Environmental Monitoring and Assessments, Vol.5, pp.113-135.

[27] Mc Grath, D., Zhangb, C. \& Carton, O. T. (2004) "Geostatistical analyses and hazard assessment on soil lead in Silvermines area, İreland, Environmental Pollution, Vol.127, pp. 239-248.

[28] Paul, R., Cressie, N. (2011) "Lognormal block kriging for contaminated soil”, Europan Journal of Soil Science, Vol.62, pp.337-345.

[29] Lark, R.M., Lapworth, D.J. (2012) "Quality measures for soil surveys by lognormal kriging”, Geoderma, Vol.173:17, pp.231-240. 
Operations Research and Applications : An International Journal (ORAJ), Vol.5, No.1, February 2018

[30] Chu, L., De Cursi, E.S., El Hami, A. \& Eid, M. (2015) "Application of Latin hypercube sampling based kriging surrogate models in reliability assessment", Science Journal of Applied Mathematics and Statistics. Vol.3: 6, pp. 263-274.

[31] Mc Kay, M G.D., Beckman, R. J. \& Conover, W.J.(1979) “A comparison of three methods for selecting values of input variables in the analysis of output from a computer code", Technometrics, Vol.21, pp.239-245.

[32] Santner, T.J., Williams, B.J. \& Notz, W.I. (2003) "The Design and Analysis of Computer Experiments", NY, Springer-Verlag.

[33] Joseph, V.R. \& Hung, Y. (2008) "Orthogonal-Maximin Latin Hypercube Designs”, Statistica Sinica, Vol.18, pp.171- 186.

[34] Van Beers W. \& Kleijnen, J.P.C. (2004) "Kriging interpolation in simulation: a survey" Technical report, Department of Information Management, Tilburg University.

[35] Lophaven, S.N., Nielsen, H.B. \& Sondergaard, J. (2002) "DACE - a MATLAB kriging toolbox" Technical report IMM-TR-2002-12, Technical University of Denmark.

[36] Dengiz, B., Bektas, T. \& Ultanir, A.E. (2006) "Simulation optimization based DSS application: a diamond tool production line industry", Simulation Modeling Practice and Theory, Vol.14, pp.296312.

\section{AUTHORS}

Muzaffer Balaban is a statistical expert at Turkish Statistical Institute. He is a candidate of $\mathrm{PhD}$ in Industrial Engineering at Başkent University. His research interests is kriging metamodels in simulation.

Berna Dengiz is the dean of Engineering Faculty at Baskent University. Her field of study is mainly simulation modeling and optimization of complex large sized systems besides heuristic optimization.
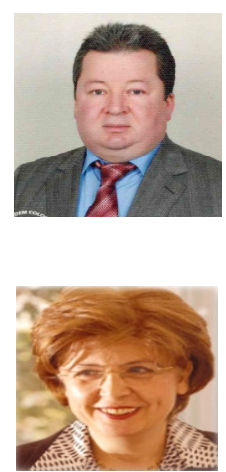